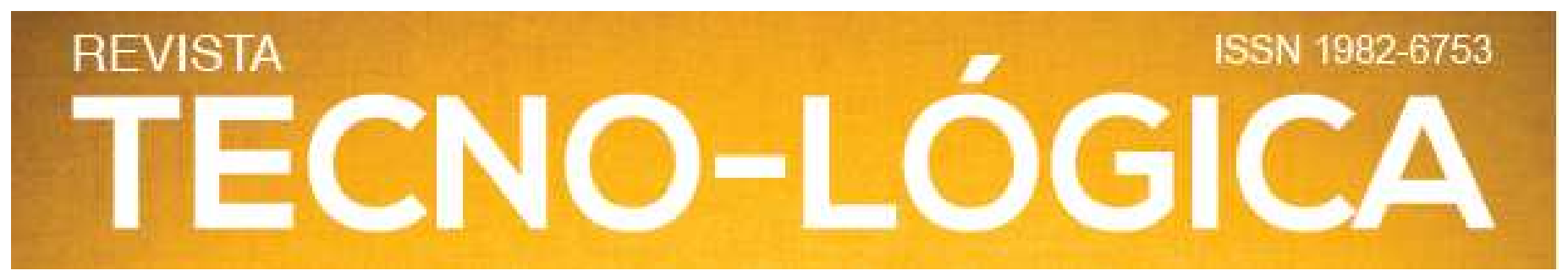

\title{
SISTEMA DE TALHADIA: DESENVOLVIMENTO DE CEPAS DE EUCALYPTUS SP. SUBMETIDAS À ADUBAÇÃO E CALAGEM
}

\author{
Douglas Edson Carvalho ${ }^{1 *}$, Ana Paula Marques Martins ${ }^{1}$, Lucas Zavoiski ${ }^{2}$, Solon Jonas Longhi ${ }^{2}$, Veridiana Padoin Weber ${ }^{2}$ \\ 1Universidade Federal do Paraná, 80210-170, Curitiba, Brasil. \\ ${ }^{2}$ Universidade Tecnológica Federal do Paraná, 85660-000, Dois Vizinhos, Brasil.
}

*E-mail: douglasedsoncarvalho@gmail.com

Recebido em: $23 / 04 / 2020$ Aceito em: $28 / 12 / 2020$ DOI: 10.17058/tecnolog.v25i1.15060

\section{RESUMO}

O objetivo do presente estudo foi avaliar a sobrevivência e o desenvolvimento inicial em número e altura média da maior brotação na condução da rebrota de cepas de uma floresta de Eucalyptus sp. com diferentes níveis de adubação e calagem em uma área de 840 $\mathrm{m}^{2}$, com espaçamento 2 × 2 m, após a colheita aos sete anos de idade, no município de Irati, Paraná. Os tratamentos foram dispostos em delineamento em blocos casualizados com quatro tratamentos de adubação e calagem com duas repetições cada, submetida à Anova e ao teste de comparação múltipla de médias a 95\% de confiabilidade. Os tratamentos foram: T1 - testemunha; T2 - fertilização recomendada; T3 - calagem recomendada e T4 - fertilização + calagem recomendadas. Houve sobrevivência de $100 \%$ das cepas sem diferença significativa entre tratamentos em três meses de avaliação. O número de brotações por cepa não diferiu estatisticamente com a aplicação de fertilizante e calagem. O crescimento em altura apresentou diferenças significativas, com a aplicação de fertilização junto à calagem apresentando o melhor resultado no crescimento em altura.

Palavras-chave: Brotações de eucalipto. Crescimento de eucalipto. Segunda rotação. Fertilidade do solo.

\section{Introdução}

Atualmente o Brasil é um dos maiores produtores de floresta plantada no mundo, as quais se estendem por 7,84 milhões de hectares, sendo elas compostas em sua grande maioria por florestas de eucalipto, pinus entre outras espécies (acácia, araucária, paricá e teca), com destaque para o segmento de

TECNO-LÓGICA, Santa Cruz do Sul, v. 25, n. 1, p. 185-194, jul./dez. $2021 \quad \begin{gathered}\text { A matéria publicada nesse periódico é licenciada sob forma de uma } \\ \text { Licença Creative Commons - Atribuição } 4.0 \text { Internacional }\end{gathered}$ http://creativecommons.org/licenses/by/4.0/

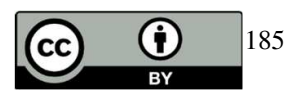




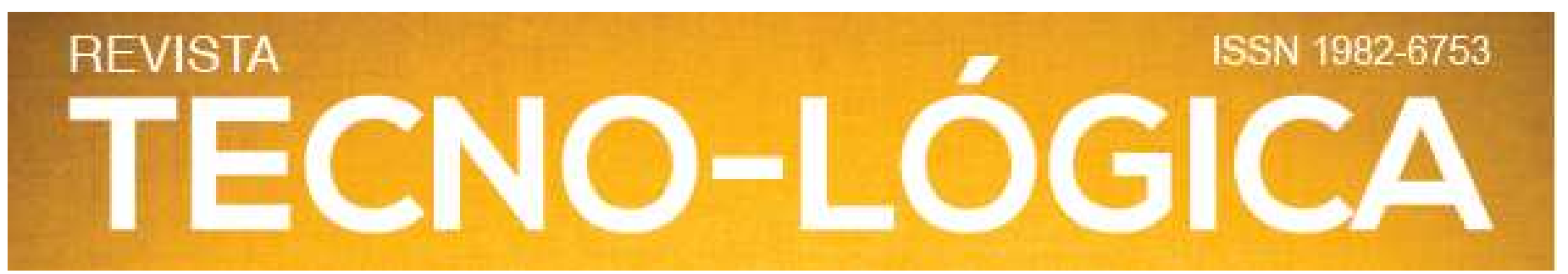

celulose e papel (cerca de $34 \%$ da produção total de florestas

A alta taxa inicial de crescimento da rebrota corresponde à plantadas) concedendo ao Brasil o quarto lugar no ranking mundial dos produtores de celulose [1].

Os primeiros estudos e plantios experimentais com o eucalipto no Brasil foram iniciados em 1904 por Edmundo Navarro de Andrade no horto florestal de Rio Claro pertencente à companhia Paulista de Estradas de Ferro, em razão do elevado consumo de lenha e dormentes [2]. Atualmente, no Brasil, grande parte dos plantios do gênero Eucalyptus é formada por híbridos, os quais procuram agregar as melhores características para cada espécie de acordo com o destino da madeira e as características de diferentes sítios [3].

O sistema de talhadia simples tem sido muito aplicado às espécies com emissão de brotos de gemas adventícias dormentes da base do tronco e/ou em lignotúberes [4]. No Brasil, esse tipo de manejo tem destaque em povoamentos de eucalipto. Em nível mundial, uma pesquisa que engloba 33 países relata que $14,4 \%$ da área total de floresta é conduzida via talhadia, o que equivale a 29 milhões de hectares [20].

Esse sistema apresenta maior taxa de crescimento inicial em comparação a plantios de mudas, podendo resultar na antecipação da próxima colheita e da produtividade máxima [5].

Povoamentos florestais conduzidos por meio da talhadia podem ser de até $27 \%$ mais baratos em comparação com a regeneração por meio do alto fuste [18].

TECNO-LÓGICA, Santa Cruz do Sul, v. 25, n. 1, p. 185-194, jul./dez. $2021 \quad \begin{gathered}\text { A matéria publicada nesse periódico é licenciada sob forma de uma } \\ \text { Licença Creative Commons - Atribuição } 4.0 \text { Internacional }\end{gathered}$ http://creativecommons.org/licenses/by/4.0/

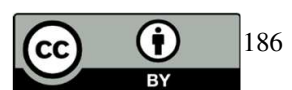

presentes nas raízes e cepas já estabelecidas [6].

A sobrevivência e a rapidez do crescimento das brotações são fatores fundamentais para a produtividade de rotações futuras. A rapidez de crescimento influencia tanto na sobrevivência do povoamento como nos tratos culturais a serem aplicados, além de interferir na homogeneidade e na produtividade da rotação seguinte [7].

Visando à ampliação da produtividade, um dos principais atributos analisados é a fertilidade do solo, a qual pode ser modificada por práticas de fertilização e correção de pH [8]. A fertilidade do solo pode ser caracterizada como a capacidade do solo em suprir os nutrientes necessários para o desenvolvimento de plantas, sendo que é possível aumentar a produtividade das culturas através de aplicações de adubos químicos, orgânicos e calcário, de modo que não ocorra deficiência de nutrientes, tornando o solo fértil [9].

No geral, acredita-se que espécies florestais não necessitam de adubação ou então, se adubados uma vez, não necessitem de adubações subsequentes de cobertura e de aplicação em próximas rotações. Porém, as perdas de produtividade após o corte e condução de uma segunda rotação variam entre 40 e $60 \%$ em relação à primeira e, consequentemente, é maior quanto mais 


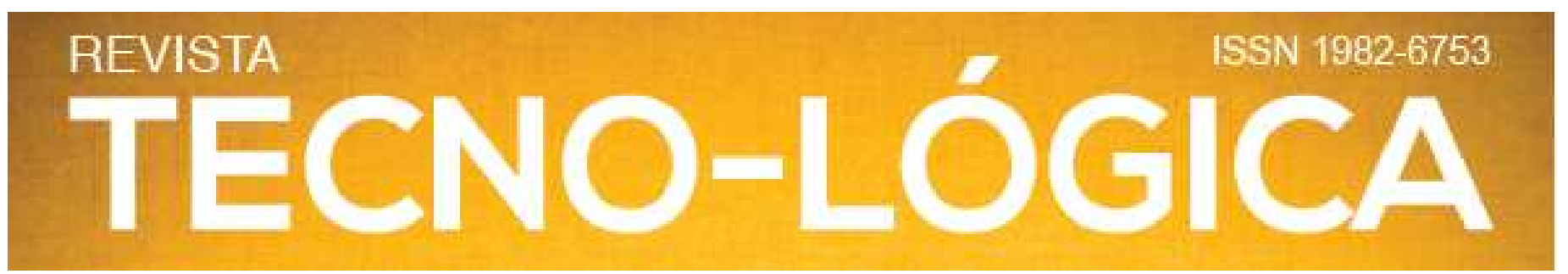

produtiva tenha sido a floresta anterior, sendo indispensável à reaplicação de fertilização na área [10].

Reduções da produção de eucalipto em plantios conduzidos por talhadia são associadas à menor disponibilidade de nutrientes [14-17], quando comparadas àqueles com a disponibilidade de tais nutrientes.

Desse modo, o objetivo do presente estudo foi avaliar a sobrevivência, o desenvolvimento inicial em número de indivíduos e altura do maior broto na condução da rebrota de cepas de uma floresta de Eucalyptus sp. com diferentes níveis de adubação e calagem.

\section{Parte experimental ou metodologia}

\section{1 Área experimental}

A área de implantação do experimento foi em uma pequena propriedade no município de Irati - PR, localizado na região Centro-Sul do Paraná, coordenadas 50³9'04'’O e $25^{\circ} 28^{\prime} 02^{\prime}$ 'S, no segundo planalto paranaense, solos predominantes classificados como argissolo vermelho amarelo, latossolo e cambissolo [11]. O clima predominante é caracterizado como subtropical úmido tipo Cfb, segundo a classificação Köppen, sem estação seca definida, com geadas frequentes e severas no período de inverno com temperatura média anual de $18^{\circ} \mathrm{C}$ e pluviosidade média mensal é de 193,37 mm e a umidade relativa do ar média mensal de 79,5\% [12].

O experimento foi conduzido em uma área de Eucalyptus sp. plantado em 2010 em uma área de aproximadamente $840 \mathrm{~m}^{2}$, com espaçamento entre linhas e entre plantas de 2 metros. $\mathrm{O}$ mesmo foi submetido ao corte raso aos sete anos de idade. O corte foi realizado em bisel com alturas entre 10 a $15 \mathrm{~cm}$ em relação ao solo.

\subsection{Tratamentos e análises}

Foi realizada análise do solo para determinação da necessidade de fertilização e correção do solo. A análise foi realizada por amostragem de três pontos dentro da área experimental (1 por bloco), com duas profundidades de coleta (0 $20 \mathrm{~cm}$ e $20-40 \mathrm{~cm}$ ) totalizando seis amostras simples, as quais foram misturadas para obter a amostra composta (500 g) encaminhada para a análise laboratorial. A recomendação de adubação e calagem, conforme análise de solo foi a seguinte: 0,694 g de calcário dolomítico e 0,902 g de NPK (2-17-17) por cepa.

A metodologia aplicada para a distribuição dos tratamentos foi Delineamento em Blocos Casualizados (DBC) com três blocos subdivididos em oito parcelas, sendo que cada parcela continha seis cepas. Dentro dos blocos foram sorteados os quatro tratamentos de adubação e correção do solo com duas parcelas cada (repetições) (Tabela 1). Portanto, três blocos $\mathrm{x}$

TECNO-LÓGICA, Santa Cruz do Sul, v. 25, n. 1, p. 185-194, jul./dez. $2021 \quad \begin{gathered}\text { A matéria publicada nesse periódico é licenciada sob forma de uma } \\ \text { Licença Creative Commons - Atribuição } 4.0 \text { Internacional }\end{gathered}$ 


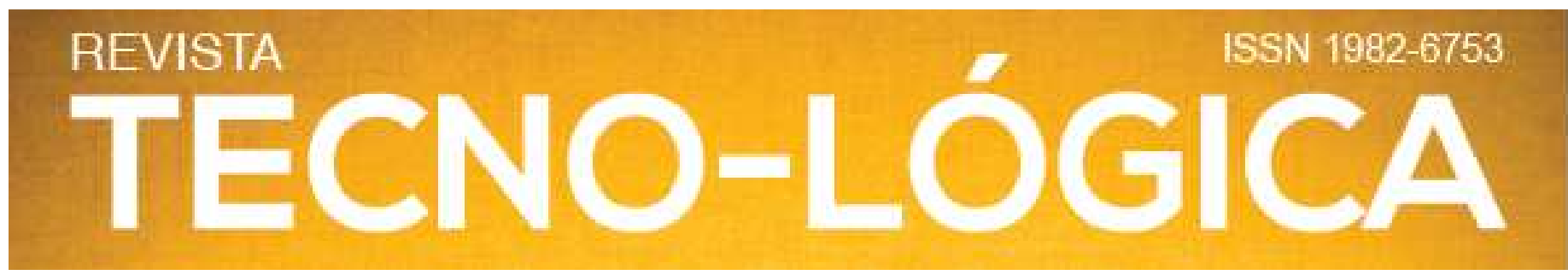

quatro tratamentos $\mathrm{x}$ duas repetições seis cepas por parcela $=144$ cepas. A aplicação dos tratamentos foi realizada após o corte raso.

Tabela 1. Tratamentos de fertilização e correção do solo aplicados aos blocos para experimento de sobrevivência e desenvolvimento inicial da rebrota de cepas de Eucalyptus sp.

\section{Tratamentos $\quad$ NPK 2-17-17 $\quad$ Calcário dolomítico}

T1(testemunha)
$\mathrm{T} 2$

T3

$\mathrm{T} 4$

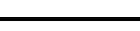

$\begin{array}{cc}- & 694 \mathrm{~g} \\ 902 \mathrm{~g} & 694 \mathrm{~g}\end{array}$

Em que NPK: adubação com Nitrogênio, fósforo e potássio.

Foi avaliada a sobrevivência, número de brotos e altura da maior brotação por um período total de 95 dias, sendo as coletas em 35, 65 e 95 dias após o corte. A sobrevivência foi determinada pelas cepas que apresentaram brotações até o período das avaliações sendo definidas como cepas sobreviventes, aquelas que apresentaram número igual ou maior que um broto; e mortas, aquelas que não apresentaram brotações.

A contagem do número de brotações foi feita visualmente, em que cada gema foi considerada uma brotação. A coleta de altura da maior brotação foi realizada com régua graduada, sendo aferida da base da cepa até o ápice da gema apical.
Os dados foram tabulados em planilha eletrônica e para as avaliações estatísticas foi utilizado o programa R Studio. Desta forma, os parâmetros (sobrevivência, número de brotos e altura da maior brotação) foram avaliados por análise de variância (ANOVA) e quando comprovadas diferenças significativas ( $\mathrm{p}<$ $0,05)$ foi realizado o teste de comparação múltipla de médias de Tukey a $95 \%$ de confiança.

\section{Resultados e discussões \\ 3.1 Número de brotações}

Após 35 dias da realização do corte raso, na primeira coleta, o experimento obteve uma brotação de $99 \%$ do total de número de cepas vindo a atingir $100 \%$ com 65 dias ( $2^{\mathrm{a}}$ coleta). Posteriormente, a 95 dias, todas as cepas apresentaram brotações, correspondendo a uma sobrevivência de 100\%. Resultados semelhantes em estudo que avaliaram 13 espécies diferentes de Eucalyptus, em que Eucalyptus urophila e Eucalyptus pilularis, tiveram $100 \%$ de cepas com brotações, porém, a sobrevivência variou entre outras espécies, como $90 \%$ para o Eucalyptus saligna no quarto mês após o corte [13].

Para as três avaliações a fim de detectar diferença significativa entre os tratamentos de adubação e correção do solo para o número de brotações por cepa foi realizada a ANOVA (Tabela 2). Na primeira avaliação (35 dias após o corte), verificou-

TECNO-LÓGICA, Santa Cruz do Sul, v. 25, n. 1, p. 185-194, jul./dez. $2021 \quad \begin{gathered}\text { A matéria publicada nesse periódico é licenciada sob forma de uma } \\ \text { Licença Creative Commons - Atribuição } 4.0 \text { Internacional }\end{gathered}$ http://creativecommons.org/licenses/by/4.0/

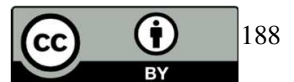




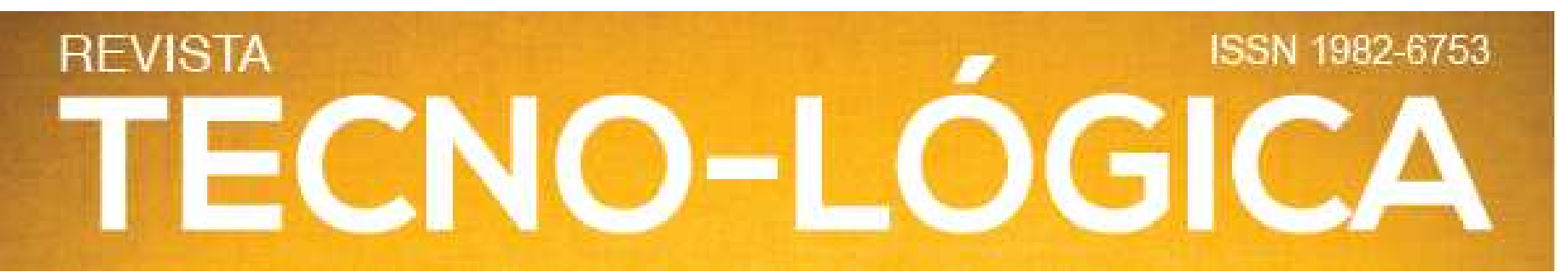

se que ocorreram diferenças significativas a $5 \%$, entre tratamentos

rejeitando a hipótese de igualdade entre tratamentos.

$\mathrm{Na}$ segunda avaliação realizada verificou-se que ocorreram diferenças significativas a $5 \%$ entre blocos e não entre os tratamentos, o que leva à conclusão de que a escolha da condução do experimento por delineamento de blocos ao acaso foi acertada, pois, no experimento há pelo menos um bloco em que outras variáveis (meio), que não os tratamentos, interferiram no número de brotações. Já na terceira avaliação verificou-se que, assim como na segunda avaliação, ocorreram diferenças significativas a $5 \%$ entre blocos e também não houve diferenças significativas entre tratamentos descartando o teste de médias para as duas últimas avaliações.

Para a primeira avaliação, a qual houve diferença significativa no número de brotos entre os tratamentos procedeuse o teste de comparação múltipla de médias de Tukey (Figura 1). Observa-se que os tratamentos 1, 2 e 3 não têm diferença estatística significativa, o mesmo pode ser afirmado em respeito aos tratamentos 2, 3 e 4 . Sendo, portanto, constatada diferença significativa a $5 \%$ de erro entre os tratamentos 1 e 4 .
Tabela 2. Análise de Variância (ANOVA) quanto ao número de brotações nas avaliações.

$1^{\text {a }}$ avaliação: 35 dias

\begin{tabular}{llllll}
\hline & G.L. & S.Q. & Q.M. & Fc & Pr>Fc \\
\hline Tratamento & 3 & 25,72 & 85,741 & 27,488 & $0,045227^{*}$ \\
Bloco & 2 & 7,72 & 38,611 & 12,379 & $0,293202^{\text {ns }}$ \\
Resíduo & 138 & 430,44 & 31,192 & & \\
\hline Total & 143 & 463,89 & & & \\
\hline
\end{tabular}

$2^{\mathrm{a}}$ avaliação: 65 dias

\begin{tabular}{llllll}
\hline & G.L. & S.Q. & Q.M. & Fc & Pr>Fc \\
\hline Tratamento & 3 & 10,52 & 35,069 & 0,7939 & $0,49928^{\text {ns }}$ \\
Bloco & 2 & 49,68 & 248,403 & 56,231 & $0,00449^{*}$ \\
Resíduo & 138 & 609,62 & 44,176 & & \\
\hline Total & 143 & 669,83 & & & \\
\hline
\end{tabular}

$3^{\text {a }}$ avaliação: 95 dias

\begin{tabular}{llllll}
\hline & G.L. & S.Q. & Q.M. & Fc & Pr>Fc \\
\hline Tratamento & 3 & 23,56 & 78,519 & 23,715 & $0,073112^{\text {ns }}$ \\
Bloco & 2 & 44,54 & 222,708 & 67,265 & $0,001631^{*}$ \\
Resíduo & 138 & 456,90 & 33,109 & & \\
\hline Total & 143 & 525,00 & & & \\
\end{tabular}

* Valor significativo; ${ }^{\text {ns }}$ Valor não significativo a 5\% de probabilidade de erro.

TECNO-LÓGICA Santa Cruz do Sul, v. 25, matéria publicada nesse periódico é licenciada sob forma de uma TECNO-LÓGICA, Santa Cruz do Sul, v. 25, n. 1, p. 185-194, jul./dez. $2021 \quad \begin{array}{r}\text { Licença Creative Commons - Atribuição } 4.0 \text { Internacional } \\ \text { http://creativecommons.org/licenses/by/4.0/ }\end{array}$ 


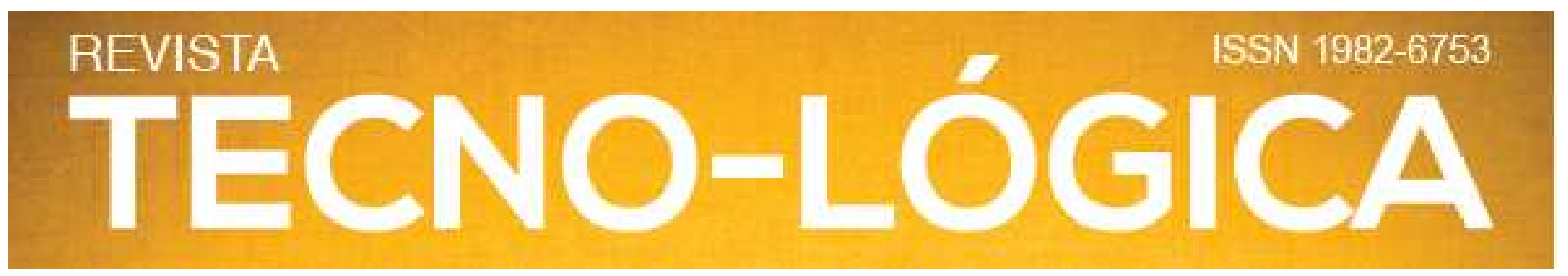

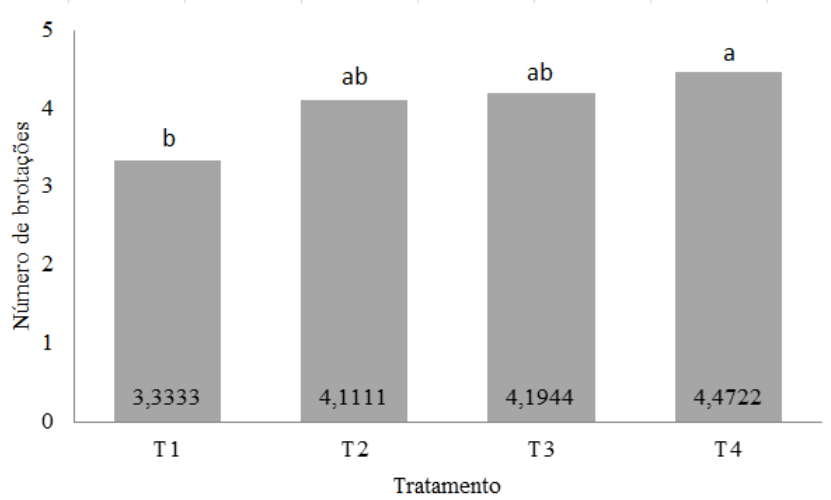

Figura 1. Comparação múltipla de médias de Tukey para o número de brotações de Eucalyptus sp. submetidos a tratamentos de adubação e correção de solo. As médias seguidas por mesma letra minúscula não diferem estatisticamente entre si.

O número de brotos do experimento apresentou uma pequena diferença na primeira coleta entre os tratamentos, entretanto, nas duas coletas após essa diferença tornou-se não significativa. Percebe-se que a média do número de brotos entre tratamentos para todas as avaliações foram semelhantes, variando de 4,25 a 5,25 brotos. Desta forma, conclui-se que a aplicação tanto de calagem como adubação não interferiram no número de brotos ao longo do tempo. Entretanto, pode-se ressaltar que se observou uma pequena redução do número médio de brotos entre a segunda e terceira avaliações, o que pode ser explicado pela competição entre os brotos de cada cepa.

O desenvolvimento é influenciado pela quantidade de brotos, pois haverá competição entre eles por recursos de crescimento, logo, diferenças de tamanho entre os brotos irão surgir se os recursos forem limitados [19], influenciando na produtividade da floresta.

Diferenças significativas no número de brotações foram observadas em análise de oito meses após o corte, ao comparar duas áreas: uma minerada (extração de bauxita) e outra não; em que a área não minerada com aplicação de fertilizantes apresentou uma brotação média de quatro brotos por cepa e a área não minerada, também com aplicação de fertilizante, com duas brotações em média [6].

Podemos afirmar que poderia ser necessário maior tempo de análise para constatação de diferenças entre o número de brotos para a presente pesquisa, uma vez que com o passar do tempo a interferência em adubação e a correção do solo têm influência mais acentuada na sobrevivência de brotos. Pois, um fator que interfere diretamente no número de brotações é a escassez de nutriente disponível [6], ou seja, a qualidade do solo.

\subsection{Altura das brotações}

Para a constatação ou não de diferenças estatisticamente significativas entre a altura da maior brotação para cepas submetidas a tratamentos de adubação e calagem foi realizada a ANOVA (Tabela 3).

TECNO-LÓGICA, Santa Cruz do Sul, v. 25, n. 1, p. 185-194, jul./dez. $2021 \quad \begin{gathered}\text { A matéria publicada nesse periódico é licenciada sob forma de uma } \\ \text { Licença Creative Commons - Atribuição } 4.0 \text { Internacional }\end{gathered}$ http://creativecommons.org/licenses/by/4.0/

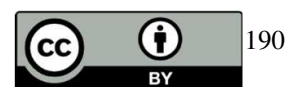




\section{REVISTA}
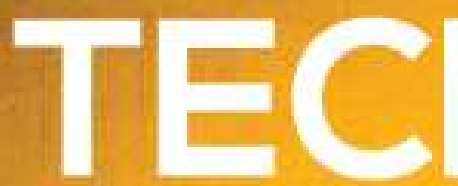

Tabela 3. Análise de Variância (ANOVA) para a altura da maior brotação nas avaliações.

$1^{\mathrm{a}}$ avaliação: 35 dias

\begin{tabular}{cccccc}
\hline & G.L. & S.Q. & Q.M. & Fc & Pr>Fc \\
\hline Tratamento & 3 & 0,1114 & 0,03714 & 1,016 & $0,38771^{\text {ns }}$ \\
Bloco & 2 & 0,1452 & 0,07259 & 1,986 & $0,14119^{\text {ns }}$ \\
Resíduo & 138 & 5,0446 & 0,03656 & & \\
\hline Total & 143 & 5,3012 & & & \\
\hline
\end{tabular}

\begin{tabular}{cccccc}
\hline \multicolumn{5}{c}{$\mathbf{2}^{\mathbf{a}}$ avaliação: 65 dias } \\
\hline & G.L. & S.Q. & Q.M. & Fc & Pr>Fc \\
\hline Tratamento & 3 & 0,7414 & 0,24714 & 3,349 & $0,020969^{*}$ \\
Bloco & 2 & 0,4024 & 0,20118 & 2,726 & $0,068979^{\text {ns }}$ \\
Resíduo & 138 & 10,183 & 0,07379 & & \\
\hline Total & 143 & 11,326 & & & \\
\hline
\end{tabular}

$3^{\text {a }}$ avaliação: 95 dias

\begin{tabular}{cccccc}
\hline & G.L. & S.Q. & Q.M. & Fc & Pr>Fc \\
\hline Tratamento & 3 & 2,8522 & 0,95073 & 7,31 & $0,000139^{*}$ \\
Bloco & 2 & 0,5158 & 0,25791 & 1,983 & $0,141556^{\mathrm{ns}}$ \\
Resíduo & 138 & 17,948 & 0,13006 & & \\
\hline
\end{tabular}

\begin{tabular}{ccc}
\hline Total 143 & 21,316 \\
*Valor significativo; ${ }^{\text {ns }}$ Valor não significativo a $5 \%$ de probabilidade de erro.
\end{tabular}

Na primeira avaliação realizada não ocorreram diferenças significativas. Já na segunda e terceira avaliações nota-se que ocorreram diferenças significativas na altura da maior brotação entre tratamentos. Portanto, é possível afirmar que a aplicação de fertilizantes e calagem contribuiu para o crescimento das brotações em altura após 65 dias do corte, pelo menos. Para a altura da maior brotação verifica-se que não houve interferência significativa do meio, que não dos tratamentos, para todas as avaliações, pois, a blocagem não foi significativa para nenhuma das avaliações.

A Figura 2 ilustra o comportamento dos tratamentos quando submetidos ao teste de comparação múltipla de médias de Tukey a $5 \%$.
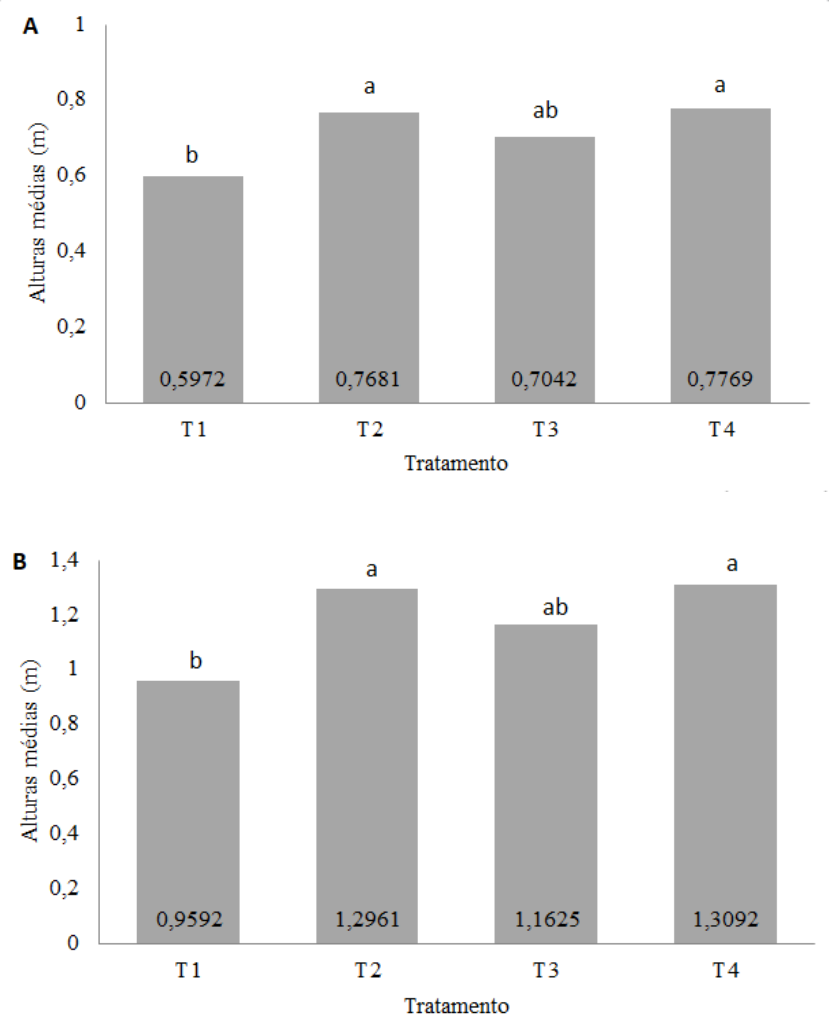

Figura 1. Comparação múltipla de médias de Tukey para a altura da maior brotação de Eucalyptus sp. submetidos a tratamentos de adubação e correção de solo aos 65 dias (a) e 95 dias (b). As médias seguidas por mesma letra minúscula não diferem estatisticamente entre si.

TECNO-LÓGICA, Santa Cruz do Sul, v. 25, n. 1, p. 185-194, jul./dez. 2021 A matéria publicada nesse periódico é licenciada sob forma de uma http://creativecommons.org/licenses/by/4.0/ 


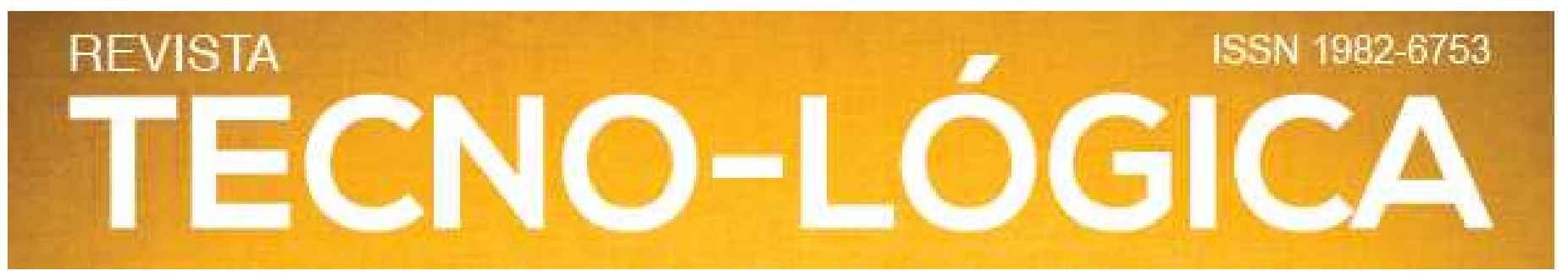

Tanto para a avaliação aos 65 quanto para a avaliação aos 95 dias, o tratamento 1 (testemunha) diferiu estatisticamente dos tratamentos 2 e 4 e não diferiu do tratamento 3 , o qual também não diferiu estatisticamente dos tratamentos 2 e 4.

Verifica-se que houve maior crescimento das brotações nos tratamentos 4 (fertilização + calagem) seguido pelo tratamento 2 (fertilização). Já o tratamento 3 (calagem), apesar de melhora no crescimento, não diferiu do tratamento T1 (testemunha).

Esse resultado demonstra que para esse experimento, o fator adubação contribuiu mais eficientemente para o crescimento em altura das brotações de Eucalytptus sp. do que a calagem, todavia, quando combinadas, os resultados são ainda superiores o que indica a necessidade de adubação e correção do solo para melhoria da fertilidade natural do mesmo e, consequentemente, maior produtividade da segunda rotação do povoamento submetido à talhadia simples.

Os valores obtidos no presente estudo apresentam-se semelhantes ao estudo de Dornelas [6], em que o autor observou diferença significativa em altura das brotações após oito meses, uma área minerada com alturas médias de $50 \mathrm{~cm}$ e uma área não minerada com alturas médias de $140 \mathrm{~cm}$, as duas submetidas à adubação.

Em comparação com o crescimento de plantas em alto fuste, pode-se ressaltar que o sistema radicular estabelecido em plantas de segunda rotação facilita a absorção de água e componentes nutritivos orgânicos e inorgânicos favorecendo o desenvolvimento inicial superior destas plantas [15-16].

\section{Conclusões}

O experimento com o gênero Eucalyptus apresentou uma sobrevivência de $100 \%$ das cepas não diferenciando entre tratamentos em três meses de avaliação. A aplicação de fertilizante e a calagem no solo não tiveram diferenças significativas no número de brotações por cepas após o período total de avaliações.

Além disso, para o crescimento das brotações, considerando a altura dos indivíduos e a aplicação de fertilização junto à calagem do solo o melhor resultado foi obtido com relação à altura para os tratamentos 2 e 4 . Dessa forma, conclui-se que a correta adubação e correção do solo na condução da rebrota resulta em maior produtividade e pode justificar o uso da condução de segunda rotação em espécies de Eucalyptus sp.

\section{COPPICE SYSTEM: DEVELOPMENT OF}

\section{EUCALYPTUS SP. SUBMITTED TO FERTILIZATION}

\section{AND LIMING}

ABSTRACT: The objective of the present study was to evaluate the survival and initial development in number and average height of greater sprouting in the management of Eucalyptus sp. strains

TECNO-LÓGICA, Santa Cruz do Sul, v. 25, n. 1, p. 185-194, jul./dez. $2021 \quad \begin{gathered}\text { A matéria publicada nesse periódico é licenciada sob forma de uma } \\ \text { Licença Creative Commons - Atribuição } 4.0 \text { Internacional }\end{gathered}$ 


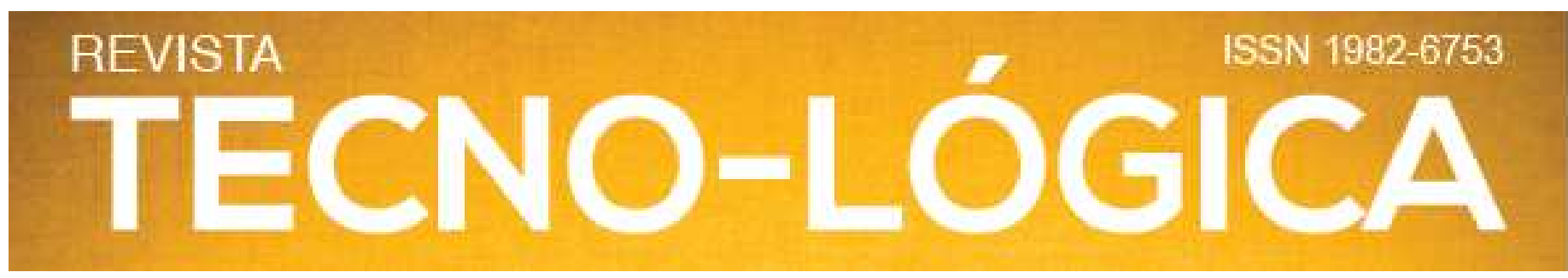

under different levels of fertilization and liming in an area of 840 $\mathrm{m}^{2}, 2 \times 2 \mathrm{~m}$ spaced apart, after harvesting at the age of seven years, in the municipality of Irati, state of Paraná. The treatments were arranged in a randomized block design with 4 treatments of fertilization and liming, with 2 repetitions each, subjected to ANOVA and multiple comparison test of averages at $95 \%$ reliability. The treatments were: T1 - control; T2 - recommended fertilization; T3 - recommended liming and T4 - recommended fertilization + liming. There was $100 \%$ survival of strains with no significant difference between treatments for three months of evaluation. Fertilizer application and liming did not have significant effect on the number of shoots per vine. The growth in height showed significant differences, in which the application of fertilization along with liming reached the best result of growth in height.

Keywords: Eucalyptus shoots. Eucalyptus growth. Second rotation. Soil fertility.

\section{Referências}

[1] IBÁ, Indústria Brasileira de Árvores. Relatório anual. 2017. 80 p. Disponível em: 〈http://iba.org/images/shared/Biblioteca/IBA_RelatorioAnual2017.pdf >. Acessado em: 23 setembro. 2017.

[2] SANTAROSA, E.; PENTEAdO JUNIOR, J. F.; GOULART F.; Transferência de tecnologia florestal: Cultivo de eucalipto em propriedades rurais: diversificação da produção e renda. Embrapa. Curitiba, 2014, 140 p.
[3] CRISMEIRE, I.. Influência da densidade do carvão vegetal na produção de silício metálico. 2014, 48 p. Dissertação de mestrado em Engenharia Florestal, Universidade Federal de Viçosa; VIÇOSA, MG, 2014.

[4] SOUZA, F. C. de; REIS, G. G. dos; REIS, M. das G. et al. Sobrevivência e Diâmetro de Plantas Intactas e Brotações de Clones de Eucalipto. Floresta e Ambiente; Rio de Janeiro, Vol. 19, n. 1, p. 44-54, 2012.

[5] CACAU, F. V.; REIS, G. G. dos; REIS, M. das G. F. et al.; Decepa de plantas jovens de eucalipto e manejo de brotações, em um sistema agroflorestal; Pesquisa Agropecuária Brasileira, Brasília, Vol.43, n. 11, p.1457-1465, 2008.

[6] DORNELAS, G. F. V.; Qualidade da brotação de Eucalyptus Saligna em área minerada, no município de Poços de Caldas, MG. 2011, 29 p. Monografia. Rio de Janeiro: Universidade Federal do Rio de Janeiro, Institutos de Florestas, 2011.

[7] GUIMARÃES, D. P.; MOURA, V. P. G.; REZENDE, G. C.; MENDES, C. J.; MAGALHÃES, J. R. G.; ASSIS T. F. de; ALMEIDA M. R. de; RESENDE M. E. A. de; SILVA F. V. da. Avaliação silvicultural, dendrométrica e tecnológica de espécies de Eucalyptus. Brasília: EMBRAPA-CPAC, 1983, 73 p.

[8] MELO FILHO, J. F. de; SOUZA, A. L. V.; SOUZA, L. da S. Determinação do índice de qualidade subsuperficial em um latosolo amarelo coeso dos tabuleiros costeiros, sob floresta natural, Revista Brasileira de Ciência do solo, Vol. 31, n. 6, p. 1599-1608, 2007.

[9] MOTA, A. C. V.; BARCELLOS, M.; Funções do solo no meio ambiente, o solo no meio ambiente, Universidade Federal do Paraná, Departamento de Solos e Engenharia Agrícola, Vol. 1, n. 1, p. 99-110, 2007.

[10] BARROS, N. F. de, NEVES, J. C. L., NOVAIS, R. F. de. Fertilidade de solos, nutrientes e produção florestal. Visão Agrícola. Florestas plantadas, Vol. 4, n. 4, p. 76-79. 2005.

TECNO-LÓGICA, Santa Cruz do Sul, v. 25, n. 1, p. 185-194, jul./dez. 2021 A matéria publicada nesse periódico é licenciada sob forma de uma http://creativecommons.org/licenses/by/4.0/

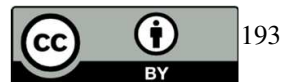




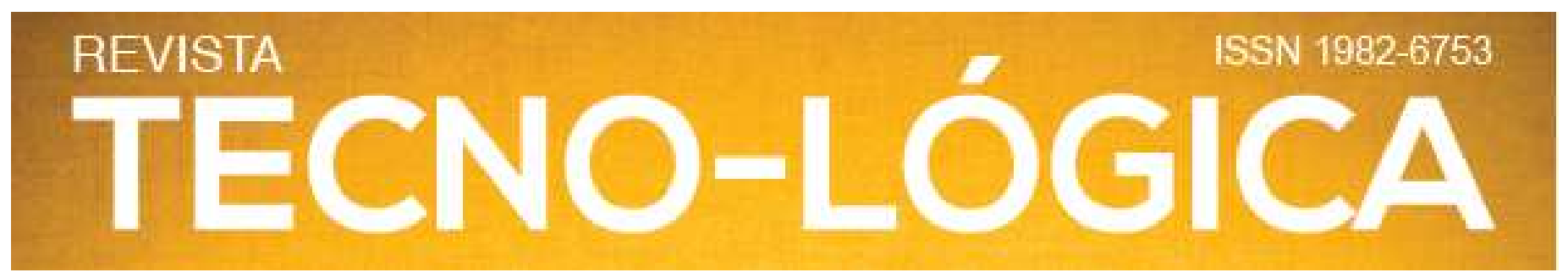

[11] PIMENTEL, A.; PUTTON, V.; WATZLAWICK, L.F.; VALÉRIO, A. F.; SAUERESSIG, D. Fitossociologia do sub-bosque do parque ambiental Rubens Dallegrave. Revista FLORESTA. Curitiba, Vol. 38, n. 3, p. 479-486, 2008.

[12] VALÉRIO, Á. V.; PUTTON, V.; WATZLAWICK, L.F.; VALÉRIO, A. F.; SAUERESSIG, D.; PIMENTEL, A. Análise da composição florística e da estrutura horizontal de uma floresta ombrófila mista Montana, município de Irati, PR BRASIL. Revista acadêmica ciências agrárias e ambientais. Curitiba, Vol. 6, n. 6, p. $137-147,2008$.

[13] HIGA, R. C. V.; STURION J. A. Avaliação da brotação de treze espécies de Eucalyptus na região de Uberaba, MG; EMBRAPA; Boletim de Pesquisa Florestal, Colombo, n.22/23, p. 79-86, 1991.

[14] ROCHA, J.H.T.; WENZEL, A.V.A.; MELO, E.A.S.C.; LIMA, Â.S.F.; HAKAMADA, R.E.; DE VICENTE FERRAZ, A.; ARTHUR JUNIOR, J.C.; GONÇALVES, J.L.D.M.; MOREIRA, G.; GONÇALVES, A.N. Responses of coppiced Eucalyptus to macro- and micronutrient application. New For., Vol. 50, p.717-731, 2019.

[15] REIS, G. G.; REIS, M. G. F. Fisiologia da brotação de eucalipto com ênfase nas suas relações hídricas. Série Técnica IPEF, Piracicaba, Vol. 11, n. 30, p. 9-22, 1997.

[16] TEIXEIRA, P. C.; NOVAIS, R. N.; BARROS, N. F.; NEVES, J. C. L.; TEIXEIRA, J. L. Eucalyptus urophylla root growth, stem sprouting and nutrient supply from the roots and soil. Forest Ecology and Management, Vol. 160, p. 263 271,2002

[17] GONÇALVES, J.L.D.M.; ALVARES, C.A.; BEHLING, M.; ALVES, J.M.; PIZZI, G.T.; ANGELI, A. Produtividade de plantações de eucalipto manejadas nos sistemas de alto fuste e talhadia, em função de fatores edafoclimáticos. Sci. For. Sci., Vol. 40, p.411-419, 2014
[18] RODE, R.; LEITE, H. G.; OLIVEIRA, M. L. R.; BINOTI, D. H. B.; RIBEIRO, C. A. A. S.; SOUZA, A. L.; SILVA, M. L.; COSENZA, D. N. Comparação da regulação florestal de projetos de fomento com áreas próprias de empresas florestais. Pesquisa Florestal Brasileira, Vol. 35, n.81, p.11-19, 2015.

[19] BARROS, K.L.C; MACEDO, R.L.G; VENTURIN, N. Capacidade de Brotação de Teca sob Regime de Talhadia Composta. Floresta Ambient., Vol. 24, p.1-7, 2017.

[20] UNRAU, A; BECKER, G; SPINELLI, R; LAZDINA, D; MAGAGNOTTI, N; NICOLESCU, V.N.; BUCKLEY, P; BARTLETT, D; KOFMAN, P. D. Coppice forests in Europe. Freiburg i. Br. Germany: Albert Ludwig University, 2018. 